\title{
Apolipoprotein CIII Measurement
}

National Cancer Institute

\section{Source}

National Cancer Institute. Apolipoprotein CIII Measurement. NCI Thesaurus. Code C82001.

The determination of the amount of apolipoprotein CIII present in a sample. 